Environmental Science \& Technology

Supporting Information for

\title{
Water and carbon footprints of electricity are sensitive to geographical attribution method
}

\author{
Md A. B. Siddik ${ }^{1}$, Christopher M. Chini², and Landon Marston ${ }^{1}$ \\ ${ }^{1}$ Department of Civil Engineering, Kansas State University, Manhattan, KS, 66506 \\ 2Department of Systems Engineering and Management, Air Force Institute of Technology, \\ 2950 Hobson Way, Wright Patterson AFB, OH 45433
}

\section{Contents of this file}

Text S1

Figures S1 to S4

Dataset S1 to S4

\section{Introduction}

The supporting information contains more detailed information on the implementation of each attribution method. Text S1 contains sections pertaining to each of the seven different attribution methods detailed in Table 1 in the main document. Additionally, Figure S1 shows the different boundaries for each of the attribution methods. Figure S2 compares water and carbon intensities for each of the attribution methods. Figure S3 compares the changes in water and carbon intensity with the balancing of electricity demand in the defined boundary. Figure S4 evaluates the coefficient of variation for the set of MSAs against normal and gamma distributions. Finally, we include relevant data sets. The first two data sets include all the water and GHG intensities for each metropolitan statistical area (MSA) across all study years. These data are in units of $\mathrm{m}^{3} / \mathrm{MWh}$ for water intensity and $\mathrm{kg} \mathrm{CO}_{2 \mathrm{e}} / \mathrm{MWh}$ for GHG intensity. The third dataset contains a list of the largest 50 MSAs by population. The final dataset contains the fuel 
composition for electricity generation for all MSAs and each evaluated geographical boundary.

\section{Text S1: Attribution Method Description and Assumptions}

\section{Interconnections}

Water consumption of each power plant is aggregated to their corresponding interconnect (Eastern Interconnection, Western Interconnection, and ERCOT). The Eastern Interconnection covers most of North America, extending from the Rocky Mountains to the Atlantic Ocean, excluding most of Texas. The Western Interconnection extends from the Rocky Mountains to the Pacific Ocean. ERCOT covers most of Texas (see Figure S1.A). The contributions to each of these interconnections can be determined using EIA form 923 and its NERC Region. Once electricity is generated and delivered to the grid it flows everywhere within an AC-interconnection (Hoffman et al., 2015). Between interconnections, there are only DC-ties so electricity has to be converted to cross the border from one interconnection into another (Hoffman et al., 2015), which can be considered negligible. We estimate water intensity from a complete mix of electricity contributed by all the power plants.

\section{Balancing authority with and without transfers}

Balancing authority maintains the demand and supply of electricity within a portion of electric grid under the control of a single dispatcher (EPA, 2018). There are 31 balancing authorities in the Eastern Interconnection and 37 balancing authorities in the Western Interconnection. The Texas interconnection consists of a single balancing authority. Balancing authorities are comprised of power control areas (PCAs; Figure S1.B). The specific PCAs and balancing authorities for each power plant can be found using the U.S. Environmental Protection Agency's (EPA) eGRID database. Chini et al. (2018) combined this database with the power plant specific information from the Energy Information Administration (EIA) to create a water footprint for each balancing authority. If an MSA draws from powerplants within multiple PCAs, all of these PCAs are assumed to supply electricity to that MSA in proportion to their generation capacity.

The Federal Energy Regulatory Commission reports annual electricity transfers between balancing authorities (or power control areas) in Form 714. Applying water and carbon intensities to distributed electricity creates a transfer of virtual water and emissions between balancing authorities. Therefore, importing electricity from a balancing authority with more water (carbon) intensive electricity production effectively raises the importing balancing authority's water (carbon) footprint. While the EIA provides monthly evaluations of water consumption for each power plant, electricity transfers are currently only available at the annual timescale within the United States. Therefore, there is a loss of temporal resolution when including transfers of electricity between balancing authorities.

\section{3. $e G R I D$ subregions}

The EPA eGRID subregions (Figure S1.C) are compromised territories between NERC region and balancing authorities that limit the import and export of electricity (EPA, 
2018). The EPA provides a representative map with approximate boundaries of the eGRID subregions. eGRID boundaries are not a rigid geographical feature; rather, eGRID's assign power plants to specific groups to better represent and report the environmental impacts. We aggregated the generation, water consumption, and carbon emission within each eGRID subregion and then calculated the water and carbon intensities associated with the eGRID subregion, similar to Peer et al. (2019). We then determined the weighted average water and carbon intensity of each MSA based on eGRID subregions supplying the MSA's electricity.

\section{Basin scale}

The United States Geological Survey (USGS) developed a hierarchical system to classify different scales of hydrologic units called the Hydrologic Unite Code (HUC). Here, we analysis hydrologic subregions (HUC-4; Figure S1.D), which is between the finer basin delineation (HUC-8) used by Tidwell et al. (2016) and the coarser spatial resolution (HUC2) used by Kelley and Pasqualetti (2013).

\section{Radius from city}

Chini et al., 2016 used the distance from the urban core to connect the water consumption embedded within nearby electricity production to the urban area where the electricity was consumed. Each MSA is depicted in Figure S1.E. We set attribution boundaries as the distance from the centroid of an MSA (evaluated at $50 \mathrm{~km}, 100 \mathrm{~km}$, and $200 \mathrm{~km}$ ). All power plants within these boundaries were assumed to provide electricity to the MSA and the associated environmental impacts were assigned to the MSA.

\section{State}

State-level analysis often focus on a single state and do not consider the embedded resources or emissions imported from outside the state boundary, leading to under accounting of embedded resources or emissions (Ruddell et al., 2014). Following the work of Ruddell et al. (2014), we assumed electricity generated within a state first satisfies instate demand and then balances the excess or deficiency by trade among the states. State boundaries within CONUS are shown in Figure S1.F. 

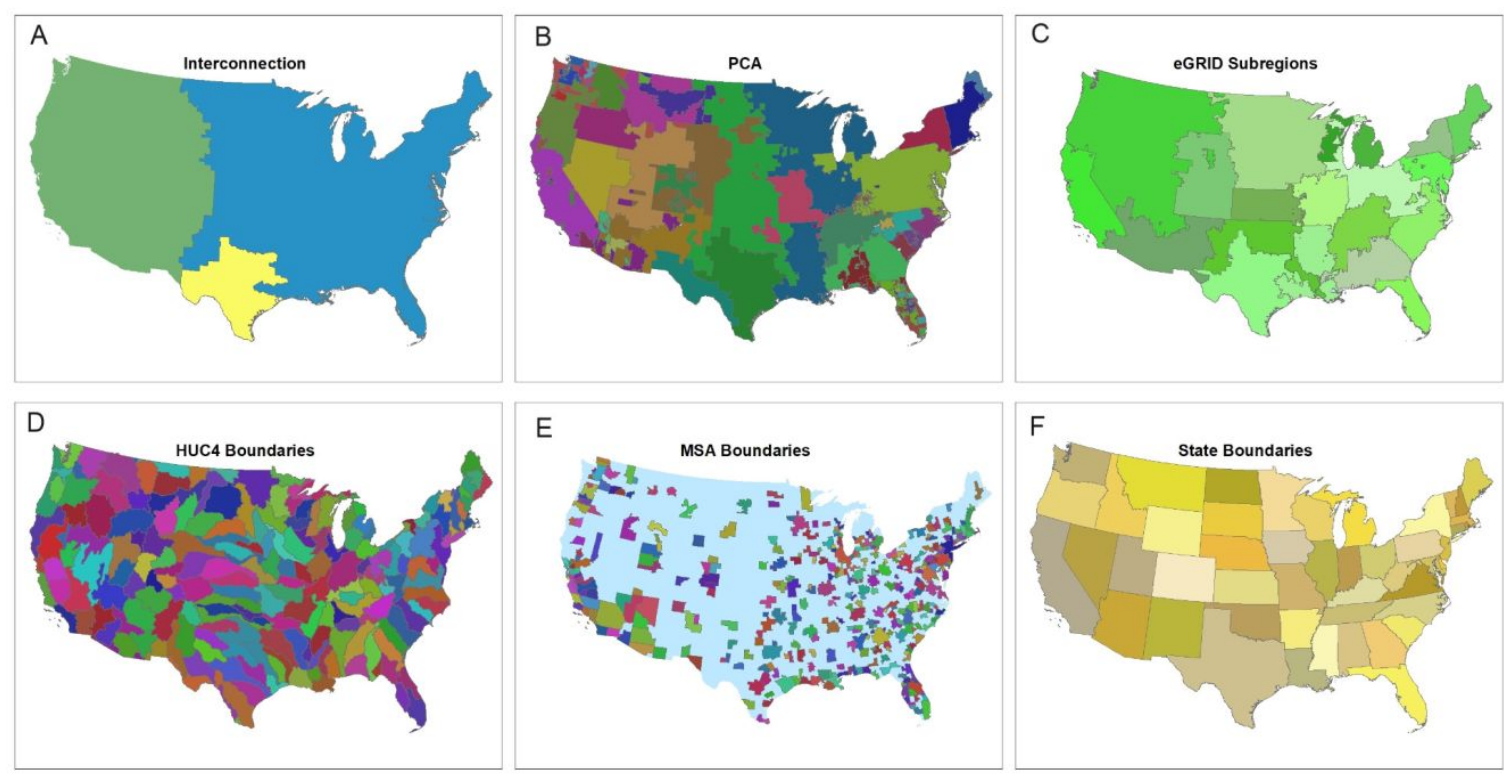

Figure S1. The geographic extent of decision boundaries for water and carbon attribution vary across the country. 


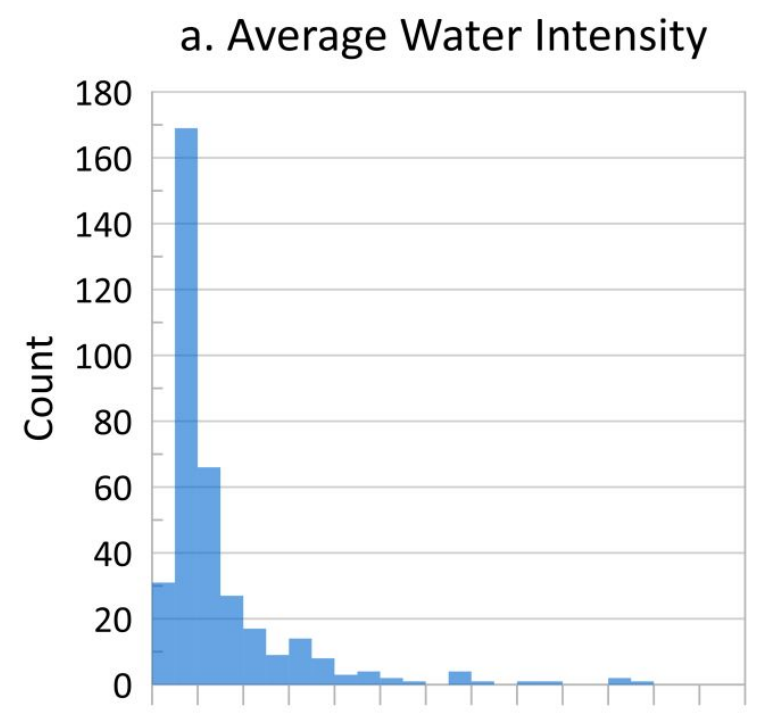

$0 \quad 4 \quad 81216202428323640444852$

Water Intensity ( $\left.\mathrm{m}^{3} / \mathrm{MWh}\right)$

c. Average Carbon Intensity

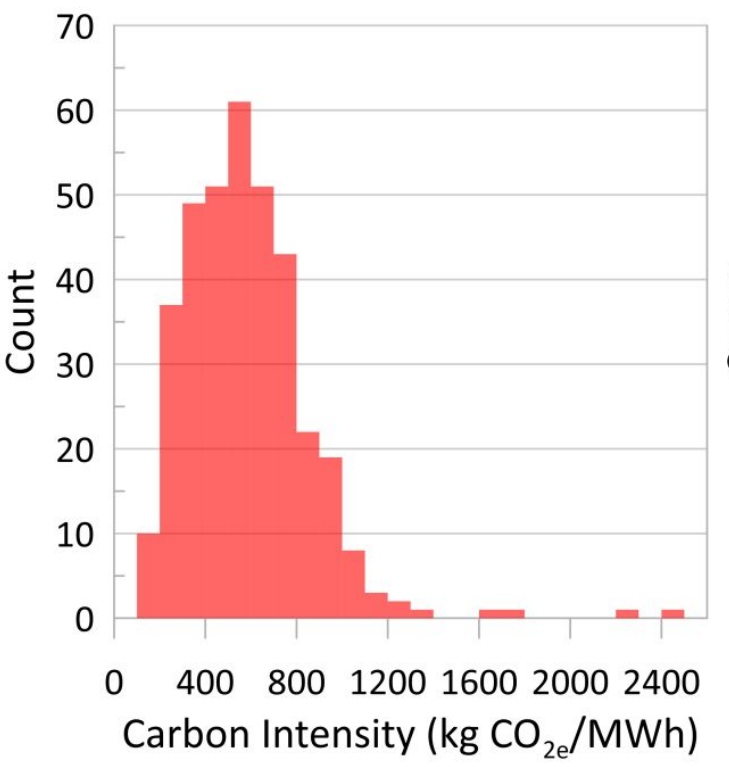

b. Coefficient of Variation
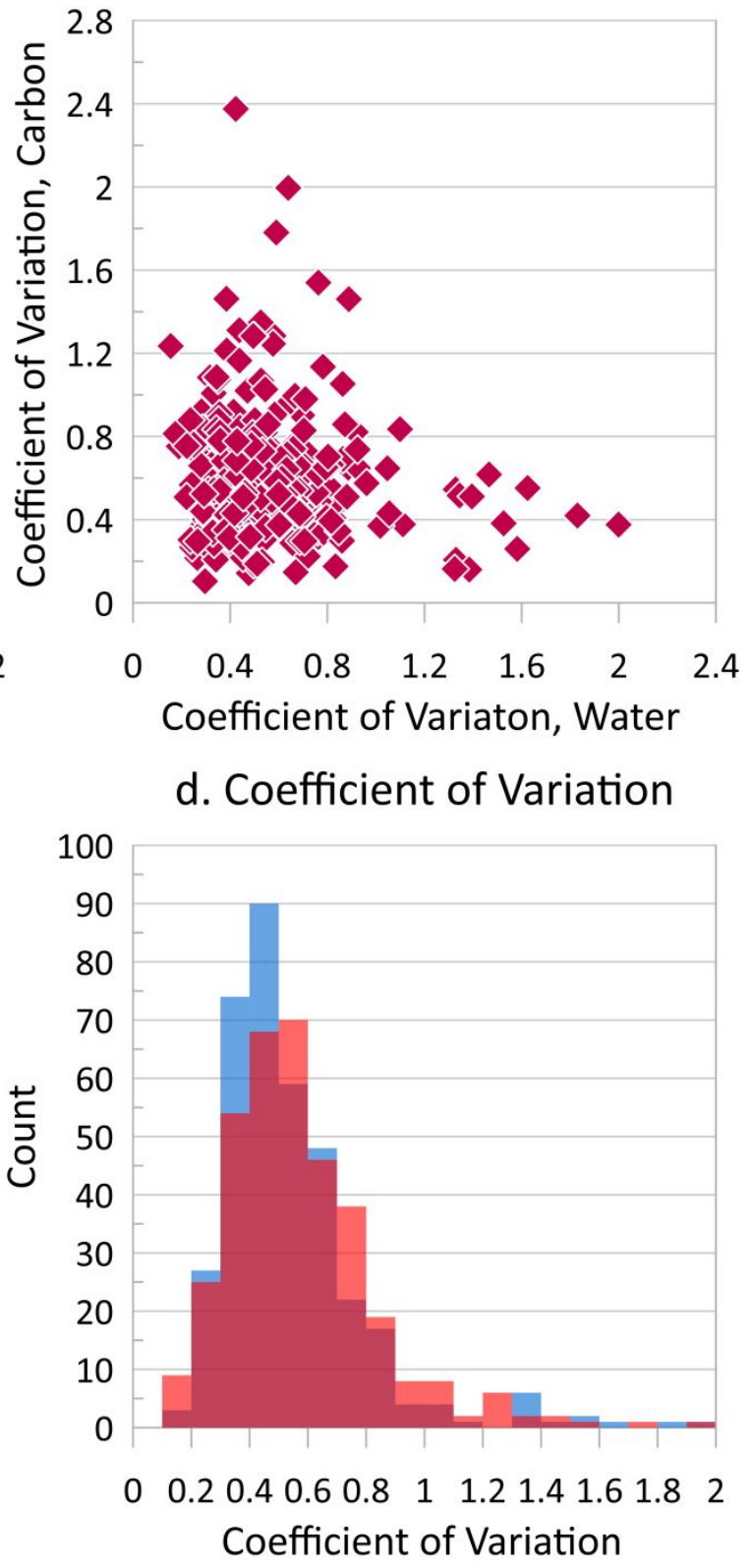

Water $\mathrm{CO}_{2 \mathrm{e}}$

Figure S2. There are tradeoffs between water intensity and carbon intensity based on the attribution method. However, these tradeoffs are location specific as the distributions of coefficient of variation are relatively similar (d) and there is no correlation between variability between water and carbon (b). Here, the number of MSAs with a given (a) water intensity and (c) carbon intensity are depicted. 


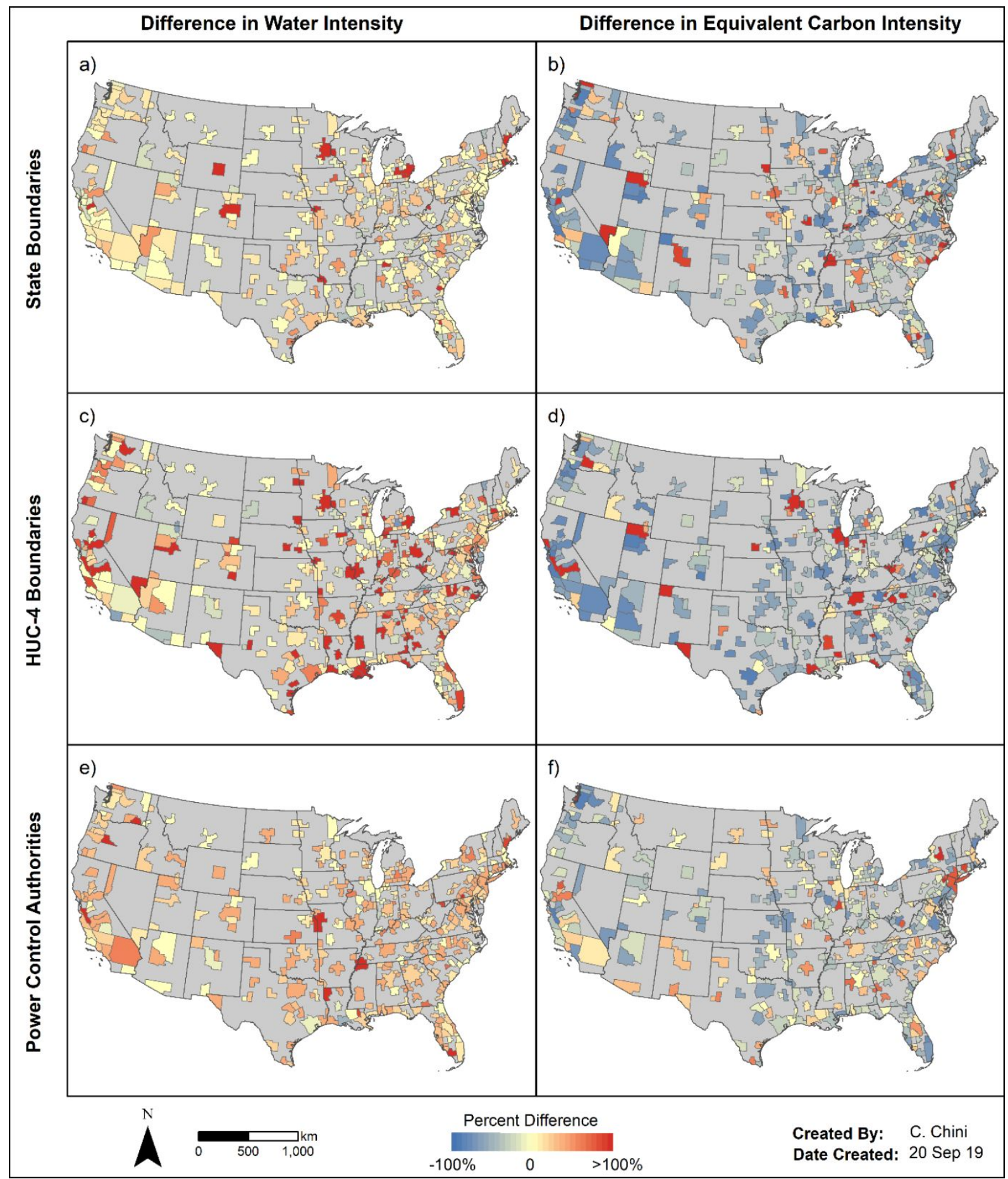

Figure S3: Differences in water and equivalent carbon intensity for each MSA was assessed with and without the inclusion of electricity transfers across state (a,b), HUC-4 (c,d), and power control authorities (PCAs; e,f). For most MSAs, the balancing of electricity through inter-boundary transfers led to minimal change in estimated water. The percent change in water intensities was the most significant for the HUC-4 attribution method. In general, the inclusion of electricity balancing across attribution boundaries led to an increase in an MSA's water intensity of electricity consumption. Conversely, the emission intensity with 
balancing power across state, HUC-4, and PCA boundaries generally decreased compared to the original boundaries.

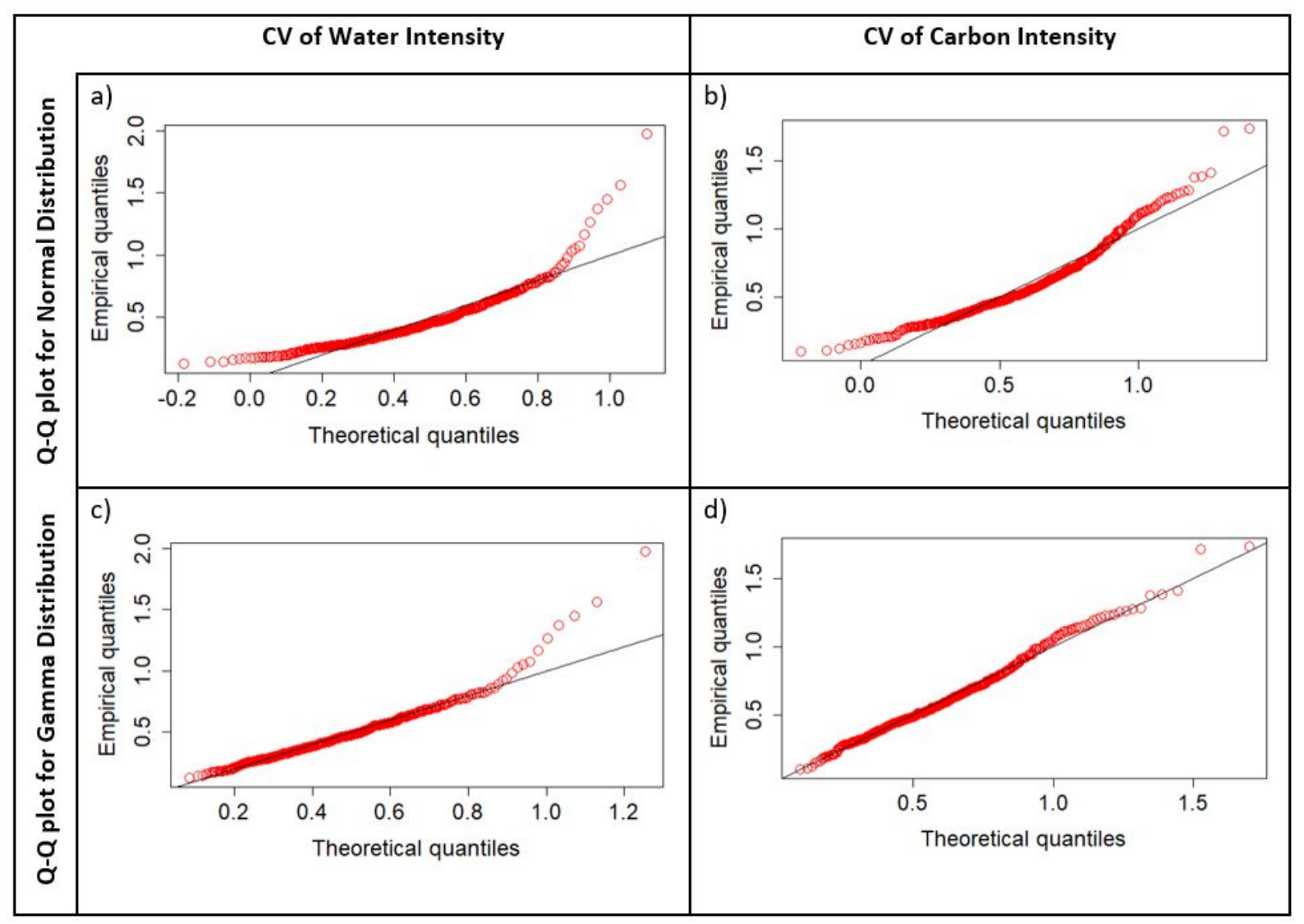

Figure S4: Co-efficient of variation $(\mathrm{CV})$ for both water and carbon intensity follow gamma distribution.

\section{References}

Chini, C. M., Djehdian, L. A., Lubega, W. N., \& Stillwell, A. S. (2018). Virtual water transfers of the US electric grid. Nature Energy, 3(12), 1115.

Chini, C. M., Schreiber, K. L., Barker, Z. A., \& Stillwell, A. A. (2016). Quantifying Energy and Water Savings in the US Residential Sector. Environmental Science \& Technology, 50(17), 9003-9012.

EPA (2018). The Emissions \& Generation Resource Integrated Database (eGRID) Technical Support Document. US Environmental Protection Agency, 106. Retrieved from https://www.epa.gov/sites/production/files/2018-

02/documents/egrid2016 technicalsupportdocument_0.pdf

Hoffman, P., \& Streit, D. (2015). United States Electricity Industry Primer. Off. Electr. Deliv. Energy Reliab. US Dep. Energy, DOE/OE, 17, 1-94. 
Kelley, S., \& Pasqualetti, M. (2013). Virtual water from a vanishing river. JournalAmerican Water Works Association, 105(9), E471--E479.

Peer, Rebecca Allyson Marie, Grubert, E., \& Sanders, K. T. (2019). A regional assessment of the water embedded in the US electricity system. Environmental Research Letters.

Ruddell, B. L., Adams, E. A., Rushforth, R., \& Tidwell, V. C. (2014). Embedded resource accounting for coupled natural-human systems: An application to water resource impacts of the western US electrical energy trade. Water Resources Research, 50(10), 7957-7972.

Tidwell, V. C., Bailey, M., Zemlick, K. M., \& Moreland, B. D. (2016). Water supply as a constraint on transmission expansion planning in the Western interconnection. Environmental Research Letters, 11(12), 124001 